\title{
Absorption and Using of Chinese Traditional Culture in Graphic Designing Course
}

\author{
Hu Anna \\ Yanbian University Academy of Fine Arts, Jilin, China, 133000
}

Keywords: Graphic design courses; Traditional culture; Absorb and Use

Abstract: Modern graphic design conveys information to the audience through the form of graphics and images. It tries to persuade the audience in non-verbal form and make the audience effectively accept the information conveyed. Modern graphic design is not only the visual decoration and beautification, but also the way of rapid human communication. For the audience under the background of commodity society, beauty in form is as important as beauty in spirit. Today, a commodity mixed with national culture and emotion is becoming the focus of market competition. Whether a designer leads the international design trend or not, the design culture concept with national characteristics has become the standard to measure. This paper starts from the influence and significance of Chinese traditional culture on graphic design courses. And then, this paper provides countermeasure on how the graphic design courses use traditional culture.

\section{Introduction}

A country's design culture and national color are closely related to its social form. If we want to achieve better development of graphic design in China, we must continue to inherit our traditional culture and adapt to the design trend. Which is the main direction of graphic design development in China. In addition, we must learn from foreign excellent design concepts and combine with our traditional culture. Only in this way can we promote world cultural exchange. At the same time, we can improve our design level and form our own unique style. Western graphic design teaching system and methods have been formed for hundreds of years, but Chinese graphic design teaching system has not yet been established. So, under the background that Chinese graphic design tends to western aesthetics, some designers have abandoned the traditional Chinese culture. They are overly westernized and want to be recognized by the international industry. However, some designers pursue western aesthetic design, but they cannot always find the connection between inner spiritual feelings and external works. After they thought they could not get recognition from international organizations, they began to add Chinese traditional culture into graphic design. They find inspiration and direction for design in the soil of traditional Chinese culture, and made remarkable achievements.

From the perspective of graphic design, the value of western aesthetics is expressed in the external expression of the works, but the traditional Chinese aesthetic value is expressed in the connotation. Only from the overall value of the work, the external expression and intrinsic value are indispensable. The inadequacy of either side will reduce the value. We discard the advantages of 
our traditional culture and simply pursue western aesthetics. It is short-sighted, blind, and shameful. From the perspective of graphic design course education, if we continue to follow the western teaching system and take western teaching content as the dominant course, we will never be able to train world-class masters who can represent Chinese traditional culture. So, it is urgent to integrate Chinese traditional culture into graphic design courses.

\section{The problems and significance of graphic design courses use Chinese traditional culture}

\subsection{The problems of graphic design courses use Chinese traditional culture}

From the application value of graphic design, it belongs to the field of commercial value. The value of Chinese graphic design works has always been at a disadvantage, mainly in the following aspects. First, there are some common problems in commodity design, such as the image features are not unique, the recognition value is not obvious, the overall design control is not in place, the product function value is not prominent in the design. Second, Chinese goods are designed according to western aesthetic values. However, the designer cannot perfectly demonstrate the characteristics who design the Chinese products under the western design standards. When these products compete with products designed by western countries, they will appear immature. Third, Chinese goods have no Chinese characteristics. Although some Chinese products use traditional symbols, these traditional cultural elements are not fully integrated with the functions of products. Fourth, the image of Chinese design lacks overall international promotion. As a result, the international market lacks the understanding of Chinese traditional culture. The outstanding added value with traditional culture has not been recognized by the international public. Which will result in the embarrassing situation that the design does not enhance the value, but reduces the value.

\subsection{The significance of graphic design courses use Chinese traditional culture}

If students are exposed to Chinese traditional culture when they study graphic design courses, their designs will incorporate traditional cultural thoughts and elements throughout their career, which will arouse their interest in learning national culture. In the future work, students can apply traditional cultural elements to their works. At the same time, they will unconsciously reveal their understanding of traditional culture in social communication, which makes people more identify with their cultivation. Integrating graphic design courses with traditional Chinese cultural elements is great helpful for teaching. Such as the teaching objectives are clearer, the teaching contents are richer, and the teaching styles are more diverse and interesting. It is profound significance to absorb Chinese traditional cultural elements, such as subject, style, composition, color and connotation.

\section{The suggestions on how the graphic designing course absorb and use Chinese traditional} culture

\subsection{Deepening students' understanding of Chinese traditional culture}

It has pointed out a new value and new confidence direction for students that the graphic designing course absorb and use Chinese traditional culture. In modern graphic design, plastic art design continues the traditional Chinese art concept. It emphasizes the artistic conception of "expressing the spirit" and pursues the romantic elegant realm of "great opportunism overcomes stupidity". It is different from the western traditional art which mainly reflects the image and vividness of works through realism. In the period of modernization, people hope to find their own aesthetic sustenance through the multi-meanings and fuzziness embodied in the "artistic 
conception". There are many advantages of Chinese traditional culture integrating into graphic design courses. It can not only guide students' moral quality positively, but also enrich their inner spiritual world. These advantages will exercise students' perception and improve their personality. Through the background understanding and features of traditional art works, those activities will improve the students' aesthetic awareness. This helps students correctly and fully understand the profound connotation of Chinese traditional culture. And through the follow-up professional skills practice, students will carry forward the traditional culture.

\subsection{Enhancing students' awareness of innovation}

The inheritance and innovation of art is the Chinese tradition. The qing dynasty painter shi tao put forward that "brush and ink should follow The Times". In the long course of history, China has accepted, absorbed and improved foreign cultures with a great mind. Finally, China makes them become localized and conform to Chinese people's ideology and living habits. After modern graphic design entered China, colleges and universities basically transplanted the Bauhaus teaching system model. As a result, the thinking mode that students are exposed to is basically rational thinking, and their graphic design theory is mainly the combination of function and form. The fusion of tradition and modernity is the basic proposition of teaching innovation in graphic design today. With the accumulation of history, many traditional Chinese cultural symbols have been recognized, and some visual designs left behind have become the visual memory by the public. In the graphic design, combining the thinking mode of traditional culture and the creative method of western expression, we can design the modern graphic design works with Chinese characteristics. At the same time, we will realize the integration and innovation of Chinese tradition and western culture.

\section{3 permeating traditional culture in classroom activities}

In graphic design, students' learning starts from the pictures and materials display of social development and changes. So, our vision has entered the field expressed by the traditional culture. The teacher guides the students to think along the traditional culture foundation, which will increase the student practice traditional culture interest. In the process of studying traditional culture, teachers have raised their awareness. At the same time, teachers throughout the connotation of traditional culture and graphic design connotation. This kind of interaction and fusion will make graphic design teaching more vivid. The teacher gave the students guidance and Suggestions on traditional cultural elements, such as painting composition, sculpture production, clothing collocation, supplies packaging and other graphic design. Teachers and students study the integration of traditional elements together. Those are the process that traditional culture permeates teaching and teaching material.

\subsection{Increasing the traditional cultural materials for designing textbooks}

In graphic design textbooks, there are few materials and pictures about traditional culture. Traditional culture is seldom added and displayed in existing textbooks to enrich the content, which ignores the charm of social and cultural accumulation. According to the survey results, 86 percent of teachers believe that teaching materials should be improved to incorporate the traditional culture. Textbooks should be improved from the use of color and the transformation of cultural vision, so as to fully display the charm of traditional culture and achieve the expected purpose. It has become a trend to incorporate traditional cultural elements into textbooks. It can give more opportunities to display traditional culture and give more inspiration to modern technology and design. Any design is based on the creation of nature and predecessors, so we should open our 
vision and expand our thinking to play the value and role of traditional culture. We should study and identify the traditional design works and take their essence for graphic designers. Figure 1 and 2 shows the design of traditional culture.

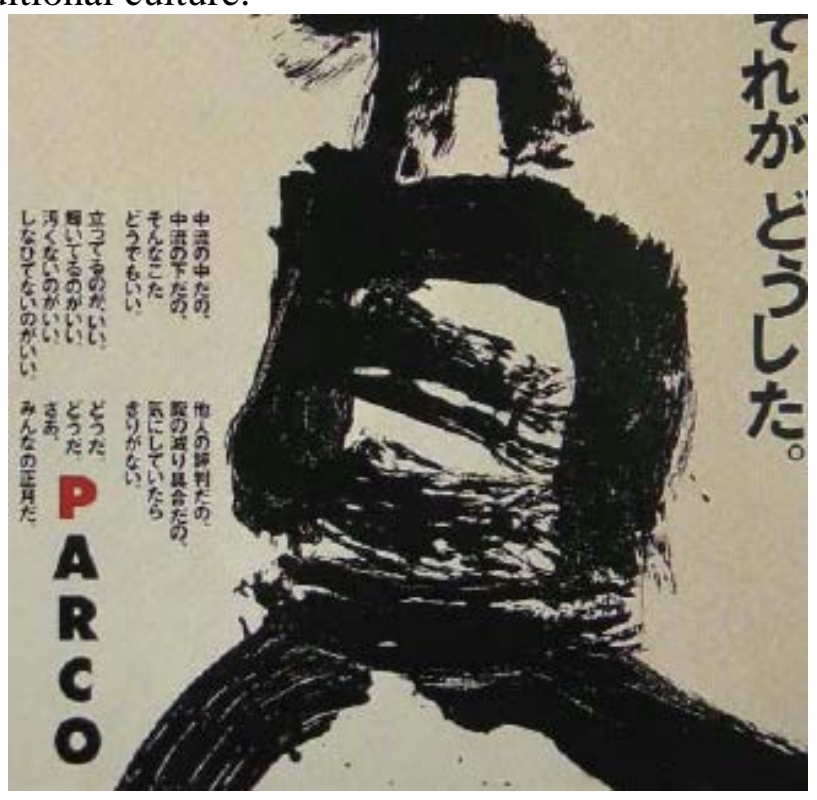

Figure 1"Corruption" written design

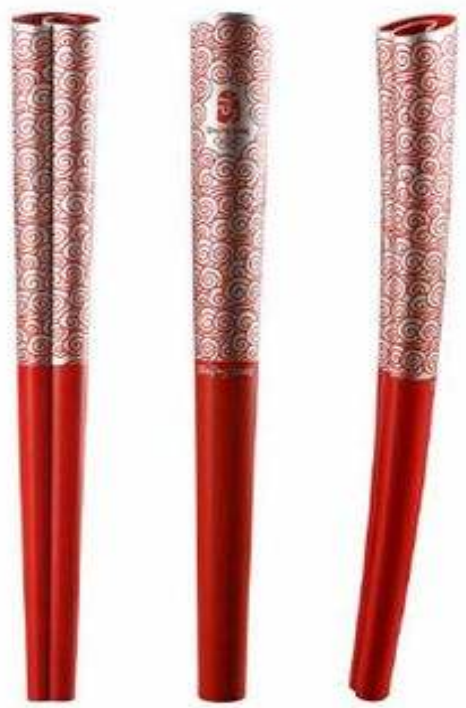

Figure 2 Olympic torch design 'lucky cloud'

\section{Conclusions}

Modern graphic design works integrated with traditional culture have become the development trend. In this way, Chinese culture can be recognized by the world, and Chinese design culture will also find a way belonging to the Chinese characteristics. At that time, the People's Republic of China is not only an economic and political power, but also a veritable graphic design power. So, from the perspective of graphic design communication, the application of Chinese traditional culture in graphic design is inevitable. However, before that, there are still many difficulties for us to overcome together. 


\section{References}

[1] Sun rui. Reflections on graphic design teaching reform in the context of the Internet era [J]. Education reform, 2012, (7): 22-24.

[2] Ouyang heng. Research on the application of Chinese traditional cultural elements in graphic design [J]. Guangxi light industry, 2016, (3):25-28.

[3] Shen liwei. Let tradition interpret modernity -- how to reflect the value of traditional culture in modern graphic design[D].Master's degree thesis of Inner Mongolia normal university, 2017.

[4] Gao mingxing. The inheritance and development of Chinese traditional graphics in modern graphic design [D]. Master's degree thesis of Northwestern university for nationalities, 2017.

[5] Sun rui. Thoughts on graphic design teaching reform in the context of the Internet era [J]. Education reform, 2015, (7) : 22-24. 